\title{
Assessment of myocardial scarring improves risk stratification in patients evaluated for cardiac defibrillator implantation
}

\author{
Igor Klem", Jonathan W Weinsaft ${ }^{2}$, Bahnson Tristram', Don Hegland ${ }^{1}$, Han W Kim, Brenda Hayes', \\ Michele A Parker ${ }^{1}$, Robert M Judd ${ }^{1}$, Raymond J Kim ${ }^{1}$
}

From 2011 SCMR/Euro CMR Joint Scientific Sessions

Nice, France. 3-6 February 2011

\section{Objective}

We hypothesized that an assessment of myocardial scarring by cardiac magnetic resonance (CMR) would improve risk stratification.

\section{Background}

Current sudden cardiac death (SCD) risk stratification emphasizes left-ventricular ejection fraction (LVEF), however the majority of patients suffering SCD have a preserved LVEF and many with poor LVEF do not benefit from ICD prophylaxis.

\section{Methods}

One hundred thirty-seven patients undergoing evaluation for possible ICD placement were prospectively enrolled and underwent CMR assessment of LVEF and scar. A comprehensive medical history including CAD risk factors, heart failure functional class (NYHA), and medications at the time of CMR was obtained in all patients. A total of 105 (77\%) patients underwent EPS within a median of 0 days (IQR $0,3.5$ ) of CMR. No patient experienced a change in clinical status in the time between CMR and EPS. 103 patients (75\%) had an ICD placed, generally during the initial evaluation, 2 days (IQR 1, 7) after enrollment.

\section{Results}

During a median follow-up of 24 months, 39 patients experienced the prespecified primary endpoint of death or appropriate ICD discharge for sustained ventricular tachyarrhythmia. Whereas the rate of adverse events steadily increased with decreasing LVEF, a sharp step-up was observed for scar size $>5 \%$ of LV mass ( $\mathrm{HR}=5.2$ [95\% CI, 2.0-13.3]). On multivariable Cox proportional hazards analysis, including LVEF and electrophysiological-study results, scar size (as continuous variable or dichotomized at 5\%) was an independent predictor of adverse outcome. Among patients with LVEF $>30 \%$, those with significant scarring $(>5 \%)$ had higher risk than those with minimalor-no (less than or equal to 5\%) scarring ( $\mathrm{HR}=6.3$ [1.4$28.0]$ ). Those with LVEF $>30 \%$ and significant scarring had similar risk to patients with LVEF less than or equal to $30 \%(\mathrm{p}=0.56)$. (Figure 1) Among patients with LVEF less than or equal to $30 \%$, those with significant scarring again had higher risk than those with minimal-or-no scarring $(\mathrm{HR}=3.9$ [1.2-13.1]). Those with LVEF less than or equal to $30 \%$ and minimal scarring had similar risk to patients with LVEF $>30 \%(\mathrm{p}=0.71)$. (Figure 2)

\section{Conclusions}

Myocardial scarring detected by CMR is an independent predictor of adverse outcome in patients being considered for ICD placement. In patients with preserved LVEF, significant scarring ( $>5 \% \mathrm{LV}$ ) identifies a highrisk cohort similar in risk to those with LVEF less than or equal to $30 \%$. Conversely, in patients with LVEF less than or equal to $30 \%$, minimal-or-no scarring identifies a low-risk cohort similar to those with preserved LVEF.

Duke University Medical Center, Durham, NC, USA

Full list of author information is available at the end of the article

(c) 2011 Klem et al; licensee BioMed Central Ltd. This is an open access article distributed under the terms of the Creative Commons 

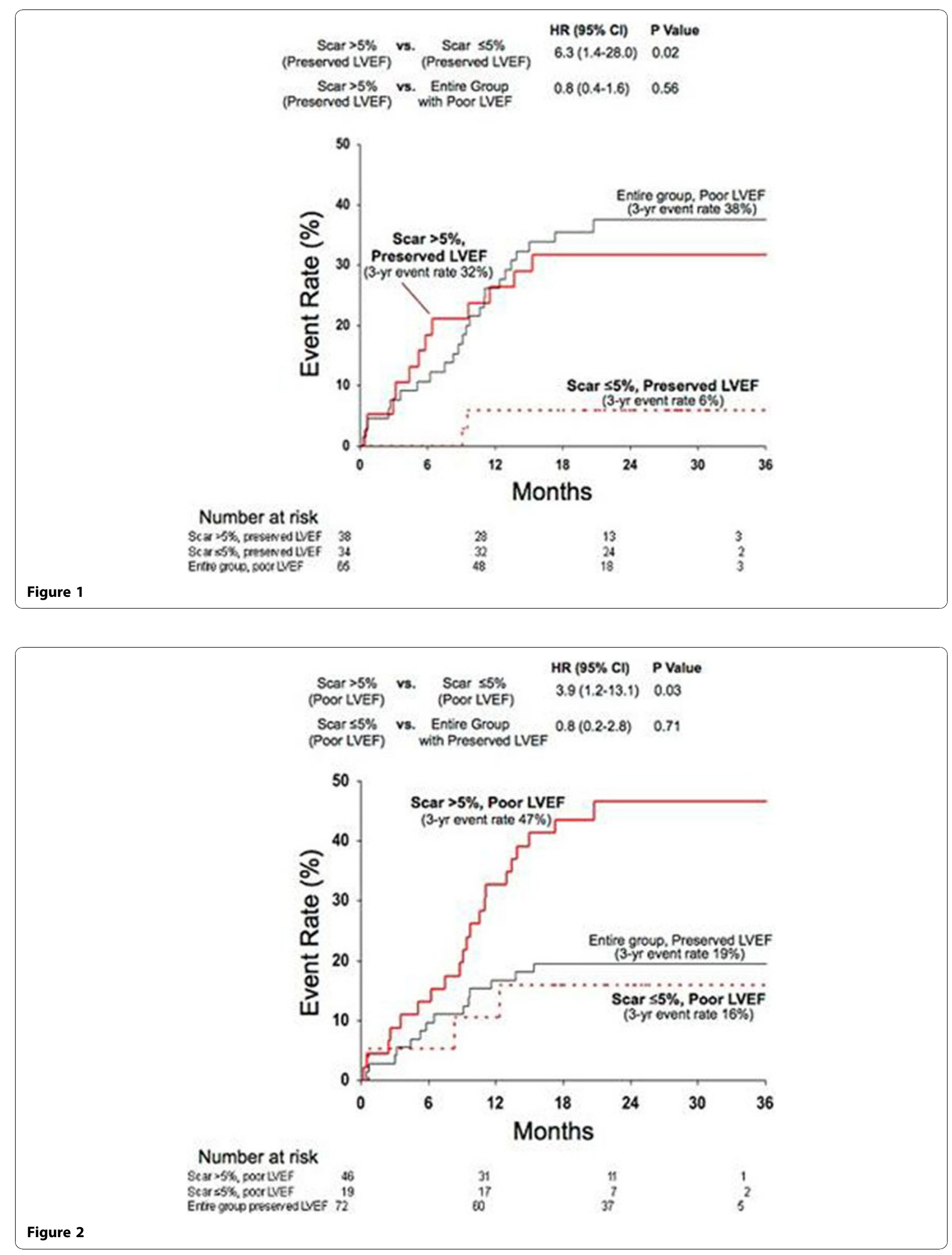


\section{Author details}

${ }^{1}$ Duke University Medical Center, Durham, NC, USA. ${ }^{2}$ Weill Cornell Medical

College, New York, NY, USA.

Published: 2 February 2011

doi:10.1186/1532-429X-13-S1-O100
Cite this article as: Klem et al.: Assessment of myocardial scarring
improves risk stratification in patients evaluated for cardiac defibrillator
implantation. Journal of Cardiovascular Magnetic Resonance 2011 13(Suppl
1):O100.

Submit your next manuscript to BioMed Central and take full advantage of:

- Convenient online submission

- Thorough peer review

- No space constraints or color figure charges

- Immediate publication on acceptance

- Inclusion in PubMed, CAS, Scopus and Google Scholar

- Research which is freely available for redistribution

Submit your manuscript at www.biomedcentral.com/submit 